\title{
Analisis statistik keterpakaian database Online Science Direct (Januari- Juni 2018) dalam mengambil kebijakan pengadaan bahan pustaka elektronik pada Perpustakaan Universitas Islam Indonesia
}

\author{
Mestika Dewi ${ }^{1}$ \\ ${ }^{1}$ Mahasiswa Pascasarjana Universitas Islam Negeri Sunan Kali Jaga \\ e-mail:dewi_mestika@gmail.com
}

\begin{abstract}
The aim of the study was to look at the price of e-journals and e-books, the average cost per access and use of content in accordance with the original price of e-journals and e-books in taking the Library Material Procurement Policy specifically in subscribing to the direct science online database. The approach used in this study is descriptive. The object of this study is the statistics on the use of e-journals and e-books on ScienDirect at the Indonesian Islamic University Library (January-June 2018). To analyze the average cost per article, the average cost per use, and the use of appropriate content using e-book download statistics, e-journal search, division journal search, division journal download, Full-Text journal compilation and subscription costs. ScienceDirect. There are 5 benchmarks and analyzed using the three metric formula by Hahn and Faulkner. The results of data analysis show that subscribing to ScienceDirect greatly benefits the Indonesian Islamic University Library judging from the use of information sources in the digital format provided by ScienceDirect causing the price of articles and access costs to be far cheaper than not subscribing to ScienceDirect.
\end{abstract}

Keywords: Database; Statistics-usage; ScienceDirect

\begin{abstract}
ABSTRAK
Tujuan penelitian adalah Untuk melihat harga e-jurnal dan e-book, biaya rata-rata per akses dan penggunaan konten yang sesuai dengan membandingkan harga asli e-jurnal dan e-book udalam mengambil Kebijakan Pengadaan Bahan Pustaka khususnya dalam melanggan database online science direct. Pendekatan yang digunakan pada penelitian ini adalah deskriptif. Objek pada penelitian ini adalah statistik keterpakaian e- jurnal dan e-book pada ScienDirect di Perpustakaan Universitas Islam Indonesia (Januari- Juni 2018). Untuk menganalisis biaya rata-rata per artikel, biaya rata-rata per penggunaan, dan penggunaan konten yang sesuai menggunakan statistik pengunduhan e-book, pencarian e- jurnal, pencarian jurnal perbagian, perngunduhan jurnal perbagian, pengundungan jurnal Full-Text serta biaya untuk melanggan ScienceDirect. Terdapat 5 tolok ukur dan di analisis menggunakan rumus tiga metrik oleh Hahn dan Faulkner. Hasil analisis data menunjukkan bahwa dengan berlangganan ScienceDirect sangat menguntungkan Perpustakaan Universitas Islam Indonesia dilihat dari keterpakaian sumber informasi dalam format digital yang di sediakan oleh ScienceDirect menyebabkan harga artikel serta biaya akses jauh lebih murah dari pada tidak melanggan ScienceDirect.
\end{abstract}

Kata kunci: Database; Statistik-Keterpakaian; ScienceDirect

\section{A. PENDAHULUAN}

Saat ini bahan pustaka yang paling banyak diminati adalah bahan pustaka dalam format digital. Hal tersebut dikarenakan maraknya penggunaan gadget yang ada di dunia, tidak terkecuali indonesia, membuat perpustakaan mau tidak mau harus menyediakan bahan pustaka dalam format digital. Salah satu cara untuk menyediakan bahan pustaka 
dalam format digital adalah dengan melanggan database online untuk menyediakan informasi yang di butuhkan oleh pengguna perpustakaan. Informasi dalam dunia perpustakaan berkembang sangat cepat, baik itu informasi dalam bentuk tercetak maupun elektronik yang berada di perpustakaan. Informasi yang mutahir dapat di peroleh dari berbagai Sumber. Salah satunya adalah Jurnal Ilmiah. Menurut Departemen Pendidikan Nasional (2008), jurnal termasuk majalah yang khusus memenuhi artikel suatu bidang ilmu tertentu, misal jurnal bidang hukum, kedokteran, kesehatan masyarakat dan lain - lain. Informasi yang tersedia pada jurnal tercetak lebih lamban diterima oleh pembacanya bila dibandingkan dengan jurnal elektronik.

Universitas Islam Indonesia sebagai lembaga perguruan tinggi swasta yang telah berkontribusi dalam menghasilkan para alumnus terbaik tentu menjadi wadah bagi para mahasaiswa/i Universitas Islam Indonesia untuk belajar, berkreasi dan membuat penelitian. Untuk membuat sebuah penelitian tentu tidak terlepas dari referensi yang akurat. Melanggan database online adalah satu cara perpustakaan untuk mendorong kegiatan penelitian. Database online adalah direktori online yang menyediakan jurnal- jurnal ilmiah yang berkualitas tinggi, diakses peer- review. Science direct adalah situs web yang menyediakan jurnal ilmiah dengan akses berlangganan ke pangkalan data penelitian yang mengandung lebih dari 4.038 e-jurnal dan 28.289 e-book.

Menyadari keunggulan jurnal elektronik dan buku elektronik tersebut, UPT Universitas Islam Indonesia telah melanggankan koleksi e-jurnal berupa database online yang salah satunya adalah ScienceDirect dengan difasilitasi adanya layanan e-jurnal (layanan referensi) yang dapat dipakai oleh mahasiswa untuk kepentingan akademik demi meningkatkan mutu pendidikan pada semua tingkat pendidikan. Dengan berbagai informasi melalui fasilitas layanan e-jurnal, akan membantu mahasiswa dalam mendapatkan informasi atau artikel yang dapat mendukung mahasiswa dalam peningkatan ilmu pengetahuan untuk menyusun skripsi, membuat penelitian dan lainnya.

ScienceDirect merupakan salah satu database online dengan harga termahal yakni Rp. 3.500.0000.000,00. Harga tersebut bukanlah harga yang murah jika dibandingkan dengan pengadaan koleksi tercetak, karena koleksi yang ada baik berupa e-jurnal dan ebook dalam ScienceDirect, bukan menjadi milik perpustakaan. Perpustakaan hanya dapat mengakses e-jurnal dan e-book dalam ScienceDirect apabila berlangganan dalam kurun waktu satu tahun, apabila tidak melanggan kembali, maka hak akses akan di cabut. ScienceDirect memberikan statistik pengunaan database online setiap enam bulan. Dengan demikian ScienceDirect dapat mengambil tindakan blokir atau tidak mengizinkan perpustakaan di tahun berikutnya apabila ketahuan melakukan pembobolan dalam mendownload e-jurnal dan e-book dalam jumlah yang banyak. Menurut kebijakan pengembangan koleksi yang dikeluarkan oleh Perpustakaan Nasional Republik Indonesia tahun 2012 salah satu prinsip pengembangan koleksi adalah pengadaan. Kebijakan pengadaan bahan perpustakaan di lakukan dengan cara pembelian, hadiah dan hibah, tukar menukar, alih media koleksi. Pembelian bahan perpustakaan dilakukan oleh Perpustakaan UII setelah daftar judul bahan perpustakaan hasil seleksi mendapatkan persetujuan dari penanggung jawab . tidak semua bahan perpustakaan yang terdaftar harus di beli dan penanggung jawab dari pembelian bahan perpustakaan adalah Kepala Pusat Pengembangan Koleksi dan Pengolahan Bahan Pustaka dengan membertimbangkan anggaran yang dimiliki oleh perpustakaan. Perpustakaan Universitas Islam Indonesia sudah tiga tahun berturut- turun melanggan ScienceDirect, dengan harga yang menurut penulis relatif mahal, maka penulis tertarik untuk mengetahui statistik keterpakaian database online ScienceDirect pada Perpustakaan Universitas Islam Indonesia dan menghitung harga e-jurnal dan e-book, biaya rata-rata per akses dan penggunaan konten yang sesuai, 
apakah dengan melanggan ScienceDirect lebih menguntungkan daripada tidak melanggan ScienceDirect dengan mencari tahu harga asli harga e-jurnal dan e-book. Penulis membatasi penelitian ini dengan mengambil data statistik penggunaan database online ScienceDirect enam bulan terakhir yaitu pada bulan Januari sampai bulan Juni 2018. Sehingga penulis menetapkan judul penelitian "Analisis Statistik Keterpakaian Database Online Science Direct (Januari- Juni 2018) Untuk Mengambil Kebijakan Pengadaan Bahan Pustaka Elektronik Pada Perpustakaan Universitas Islam Indonesia”.

\section{B. TINJAUAN PUSTAKA}

\section{Pengertian Pengadaan Koleksi Bahan Pustaka}

Pengadaan bahan pustaka merupakan salah satu pelayanan teknis pada perpustakaan dalam usaha untuk memberikan informasi yang dibutuhkan oleh pengguna perpustakaan sesuai dengan perkembangan zaman. Melalui pengadaan bahan pustaka, perpustakaan berusaha untuk menghimpun bahan pustaka yang akan dijadikan koleksi perpustakaan, baik berupa buku, e-book, jurnal, e-jurnal, majalah, mikrofilm, mikrofis, piringan hitam, video, kaset, CD- ROM dan lainnya.

Menurut Darmono (2001) Pengadaan bahan pustaka merupakan rangkain dari kebijakan pengembangan koleksi akhirnya akan bermuara pada kegiatan pengadaan bahan pustaka, sedangkan menurut Sulistyo-Basuki (2001) pengadaan bahan pustaka merupakan konsep yang mengacu pada prosedur sebuah kegiatan pemilihan untuk memperoleh dokumen, yang di gunakan untuk mengembangkan dan membina koleksi atau himpunan dokumen yang di perlukan untuk memenuhi kebutuhan informasi serta mencapai sasaran unit informasi.

Menurut pendapat ahli di atas dapat disimpulkan bahwa pengadaan bahan pustaka merupakan proses awal sebuah kegiatan untuk menghimpun, menyeleksi guna untuk mendapatkan dokumen yang relevan sesuai dengan kebutuhkan.

\section{Pengertian Statistik}

Ilmu perpustakaan merupakan salah satu mutli-disiplin ilmu, karena itu ilmu perpustakaan kerap bersanding dengan ilmu lainnya. Istilah statistik sering disesuaikan dengan bidang kegiatan dan ilmu yang digunakan. Menurut Jaya dan Ardat (2013) statistik adalah rekapitulasi dari fakta yang berbentuk angka- angka disusun dalam bentuk tabel dan dianggram yang mendeskripsikan suatu permasalahan. Sedangkan menurut UndangUndang Republik Indonesia No. 7 tahun 1960, menyebutkan bahwa statistik merupakan keterangan berupa angka- angka yang memberikan gambaran yang wajar dari seluruh ciriciri kegiatan dan keadaan masyarakat Indonesia. Sehingga dapat disimpulkam bahwa statistik adalah rekapitulasi data berupa angka- angka yang di gunakan untuk mendeskripsikan keadaan, kegiatan dan masalah.

\section{Pengertian Database}

Database atau yang biasa disebut dengan istilah basis data, terdiri dari dua kata, basis dan data. Menurut Musyawarah (2005) Database adalah sekumpulan data yang berisi informasi mengenai satu atau beberapa object. Sedangkan menurut Abdul Kadir seperti dikutip Khusnia dan Riasti (2014) Database menyatakan merupakan suatu bentuk pengelolaan data yang ditujukan agar pengaksesan terhadap data dapat dilakukan dengan mudah. Menurut Deborah Kurniawati \& Edy Prayitno seperti dikutip Nugroho dan Purnama (2012) basis data atau database adalah kumpulan terintegrasi dari elemen data yang secara logika saling berhubungan.

Sehingga dapat disimpulkan database adalah sekumpulan data yang berisi informasi 
yang terintegrasi saling berhubungan antara satu dengan lainnya dan di simpan dalam filefile terpisah.

\section{Pengertian E-book}

E-book adalah bentuk digital dari sebuah buku yang berisi informasi tertentu. E-book memiliki format penyajian yang runtut, baik bahasanya, tinggi kadar keilmuannya, dan luas pembahasannya. Menurut Wiji Suwarno (2011) , e-book adalah versi elektronik dari buku. Jika buku pada umumnya terdiri dari kumpulan kertas yang berisi teks atau gambar, maka e-book berisi informasi digital yang juga dapat berwujud teks atau gambar. Sedangkan menurut Putut Laxman Pendit seperti dikutip Prabowo dan Harianto (2013) ebook adalah bentuk buku elektronik secara sederhana bias dilihat dalam bentuk teks yang tersaji dalam bentuk dokumen yang dibuat dengan wordprocessor, HTML, atau XML.

Sedangkan menurut Supriadi (2013) merupakan sebuah publikasi yang terdiri dari teks, gambar, vidio, maupun suara dan diterbitkan dalam bentuk digital yang dapat dibaca komputer maupun perangkat elektronik lainnya. Jadi, dapat dijelaskan e-book merupakan merupakan publikasi yang tersusun secara sistematis seperti buku, akan tetapi dalam format digital atau dalam versi elektronik. Sehingga dapat di simpulkan bahwa e-book adalah distribusi muatan isi buku dalam versi digital. Adapun tujuan dari pembuatan ebook menurut Prabowo dan Harianto (2013) adalah:

1. Untuk melestarikan koleksi perpustakaan.

2. Memberikan layanan perpustakaan digital.

3. Efesiensi ruangan karena e-book lebih menghemat ruangan.

4. Menciptakan koleksi yang tak terbatas ruang dan waktu.

5. Biaya lebih murah.

Kewajiban atau tugas pustakawan dalam pelayanan kepada pengguna pepustakaan adalah memberikan pendidikan, bimbingan, layanan dan kerjasama kepada pemustaka dalam memilih sumber informasi yang di butuhkan dan cara penelusurannya serta memberikan alternatif dalam format elektronik, sehingga tidak ada alasan untuk pemustaka tidak mengunjungi perpustakaan, karena tersedianya perpustakaan dalam versi web yang memuat konten digital.

\section{Pengertian E-jurnal}

E-jurnal merupakan segala terbitan berseri atau berperiode yang memiliki nilai bermacam informasi yang penyebarannya dalam bentuk format digital atau dalam versi elektronik. Menurut Reitz seperti dikutip Rusydi (2014) menggunakan istilah jurnal elektronik (electronic journals) untuk online journal mendefinisikan bahwa jurnal elektronik sebagai versi digital dari jurnal tercetak, atau jurnal seperti dalam format publikasi elektronik tanpa versi tercetaknya, tersedia melalui email, web dan akses internet. Baik dalam format online journals maupun jurnal tercetak merupakan jurnal dalam cakupan terbitan berseri. Perbedaannya terletak pada media aksesnya dimana jurnal format tercetak berbahan baku kertas dapat dibaca langsung, sedangkan journal online berupa jurnal dalam format digital dan untuk membacanya diperlukan akses internet terlebih dahulu.

Sehingga dapat disimpulkan e-jurnal merupakan pendistribusian jurnal dalam bentuk format digital atau dalam versi elektronik. Adapun beberapa manfaat menurut Rusydi (2014) adanya e-journal diantaranya adalah:

1. Merangsang minat baca.

2. Memudahkan akses dan publikasi secara luas. 
3. Meningkatkan daya saing, kualitas. kreatifitas, ilmu dan pengetahuan para peneliti/penulis.

4. Pembuktian kualitas dan kredibilitas institusi penerbit pada akhirnya akan menjadi media promosi.

5. Meningkatkan rangking perguruan tinggi.

Pemanfaatan e-journal merupakan layanan cyber dengan beragaminformasi pada sumber dari jaringan global, tentu di perlukan peran dari pustakawan sebagai penyaji informasi memerlukan keahlian khusus bagaimana agar layanan tersebut berguna dan diminati oleh pemustaka.

\section{METODOLOGI PENELITIAN}

Penelitian mengenai Analisis Statistik Keterpakaian Database Online Science Direct (Januari- Juni 2018) Untuk Mengambil Kebijakan Pengadaan Bahan Pustaka Elektronik Pada Perpustakaan Universitas Islam Indonesia menggunakan metode pendekatan Deskriptif .

Penelitian deskriptif Menurut Arikunto (2010) yaitu mengumpulkan data berdasarkan faktor- faktor yang menjadi pendukung terhadap objek penelitian, kemudian menganalisa faktor- faktor tersebut untuk dicari peranannya. Sedangkan Menurut Sugiyono (2011) "Penelitian deskriptif adalah penelitian yang dilakukan terhadap variabel mandiri, yaitu tanpa membuat perbandingan atau menghubungkan dengan variabel lain".

Penelitian ini menganalisis statistik peminjaman e-jurnal dan e-book untuk membantu analisis dalam penelitian ini.

\section{HASIL DAN PEMBAHASAN}

\section{Gambaran Science Direct}

Science Direct membantu peneliti mendapatkan pengetahuan, menghasilkan lebih banyak ide, dan menjawab pertanyaan paling mendesak dalam waktu lebih singkat. Science Direct adalah database yang berisi kumpulan dokumen full-text yang berkualitas yang telah diperiksa oleh peer-review Elsevier. Science Direct juga menyediakan fungsi pencari dokumen yang canggih pada bagian Search dan Retrieval tools seperti informasi yang terintegrasi dengan sumber-sumber eksternal dalam bentuk audio dan video dan seperangkat data.

Pencarian dokumen pada ScienceDirect adalah :

1. Cara mencari dokumen dengan Advanced search

Masuk ke menu Advanced Search untuk mencari dokumen yang spesifik atau anda dapat juga mencari dengan mengakses Search History (diperlukan registrasi untuk melakukan hal ini).

2. Anda dapat melakukan pencarian menyeluruh pada semua sumber database dalam ScienceDirect atau lebih spesifik pada jurnal saja, buku saja, referensi atau gambar.

3. Masukkan kata kunci pencarian yang anda inginkan pada tempat yang disediakan, kemudian pilih di lingkup mana anda akan melakukan pembatasan pencarian seperti artikel saja, judul saja dan sebagainya, anda dapat juga menggunakan operator Boolean (seperti AND dan OR) untuk melakukan kombinasi pencarian.

4. Lakukan pencarian anda pada jurnal, buku, artikel bebas akses, subyek tertentu dan/atau berdasarkan tahun. 
5. Cara mencari dokumen dengan Quick search Masukkan kata kunci pada kotak pencarian dan tekan klik icon pencarian (search icon) untuk mencari dokumen yang anda inginkan.

Berlangganan ScienceDirect memberi akses ke artikel dari 3.800 jurnal elektronik dan lebih dari 37.000 buku elektronik. Bahkan tanpa berlangganan, ScienceDirect menghadirkan akses dengan lebih dari 250.000 publikasi yang dapat di akses secara gratis. Dan cara melakukan pencarian dalam ScienceDirect relatif mudah.

\section{Gambaran Perpustakaan Universitas Islam Indonesia}

Perpustakaan Universitas Islam Indonesia terletak pada Gedung Moh. Hatta, Kampus Terpadu Universitas Islam IndonesiaJalan Kaliurang KM. 14,5 Sleman Yogyakarta 55584 dan nomor telepon : +62 274898444 serta email: perpustakaan@uii.ac.id. Pada tahun 2009 Yayasan Badan Wakaf UII membangun Gedung Perpustakaan yang memiliki konsep modern, baik dari fasilitas fisik maupun layanannya. Namun baru dimulai membangun landasan untuk calon Fondasi bangunan, mendadak ditemukan Batu Situs yang ternyata adalah sebuah bangunan Candi Tua dengan Ganesha yang dipercaya sebagai Dewa simbol Ilmu Pengetahuan. Ini suatu kebetulan yang sangat tepat dengan peruntukan calon gedung yang akan dibangun yaitu Gedung Perpustakaan sebagai Pusat Belajar dan Mengajar Ilmu Pengetahuan. Setelah Candi diekskavasi maka pembangunan Gedung dilanjutkan hingga selesai.

Fasilitas perpustakaan Universitas Islam Indonesia Adalah :

1. Koleksi terdiri atas buku, Atlas kedokteran, Surat kabar, Jurnal dan Majalah kedokteran, Kaset, CD.

2. Menggunakan Sistem Informasi Perpustakaan (SIMPUS) yang telah terintegrasi dengan SIM UII untuk kemudahan pengelolaan anggota, penelusuran dan peminjaman.

3. Laboratorium Multimedia

4. Ruang ber-AC dilengkapi meja belajar dan meja diskusi

5. Layanan Fotokopi

Universitas Islam Indonesia, dilihat dari data yang diperoleh dari data Direktorat Akademik Universitas Islam Indonesia pada semester Ganjil 2018 , bahwa jumlah mahasiswa tercatat \pm 23.000 (dua puluh tiga ribu) orang.

\section{Statistik Pengunduhan E-book}

ScienceDirect memberikan statistik data pengunduhan e-book kepada UPT Perpustakaan Universitas Islam Indonesia setiap enam bulan sekali. Adapun pengunduhan pada bulan januari- juni 2018, dapat di lihat pada tabel berikut:

Tabel 1.1 Tabel pengunduhan e-book bulan Januari- Juni 2018

\begin{tabular}{|l|l|}
\hline \multicolumn{1}{|c|}{ Bulan } & \multicolumn{1}{c|}{$\mathbf{2 0 1 8}$} \\
\hline Januari & 189 \\
\hline Februari & 17.453 \\
\hline Maret & 602 \\
\hline April & 614 \\
\hline Mei & 420 \\
\hline
\end{tabular}




\begin{tabular}{|l|l|}
\hline Juni & 868 \\
\hline Total & 20.146 \\
\hline
\end{tabular}

Dari Tabel 1.1 dapat dilihat bahwa e-book pada ScienceDirect paling banyak di unduh pada bulan Februari. Adapun 50 top e-book yang sering di download, dapat di lihat pada tabel berikut:

Tabel 1.2 Top List Judul e-book

\begin{tabular}{|r|l|r|}
\hline 1 & 16th Edition IEE Wiring Regulations & 4 \\
\hline 2 & A Comprehensive Database of Tests on Axially Loaded Piles Driven in & 12 \\
\hline 3 & A Global Perspective on Private Higher Education & 1 \\
\hline 4 & A Guide to Microsoft Excel 2013 for Scientists and Engineers & 19 \\
\hline 5 & A Librarian's Guide to Graphs, Data and the Semantic Web & 50 \\
\hline 6 & A Machine-Learning Approach to Phishing Detection and Defense & 14 \\
\hline 7 & A Practice of Anesthesia for Infants and Children (Fourth Edition) & 2 \\
\hline 8 & A Primer for Financial Engineering & 10 \\
\hline 9 & A Study of Black Hole Attack Solutions & 21 \\
\hline 10 & A Worldwide Yearly Survey of New Data in Adverse Drug Reactions & 1 \\
\hline 11 & Abstract Domains in Constraint Programming & 56 \\
\hline 12 & Activated Carbon Fiber and Textiles & 29 \\
\hline 13 & Active Coatings for Smart Textiles & 96 \\
\hline 14 & Active Nitrogen & 1 \\
\hline 15 & Adaptive Radar Resource Management & 21 \\
\hline 16 & Adolescent Addiction & 1 \\
\hline 17 & Adsorption Processes for Water Treatment & 23 \\
\hline 18 & Adsorption, Ion Exchange and Catalysis & 11 \\
\hline 19 & Adult Attachment & 14 \\
\hline 20 & Advanced Composite Materials for Aerospace Engineering & 21 \\
\hline 21 & Advanced Fixed Income Analysis (Second Edition) & 26 \\
\hline 22 & Advanced Thermodynamics for Engineers (Second Edition) & 47 \\
\hline 23 & Advances in 3D Textiles & 45 \\
\hline 24 & Advances in Artificial Transportation Systems and Simulation & 40 \\
\hline 25 & Advances in Battery Technologies for Electric Vehicles & 21 \\
\hline 26 & Advances in Braiding Technology & 49 \\
\hline 27 & Advances in Computers Vol: 97 & 36 \\
\hline 28 & Advances in Filament Yarn Spinning of Textiles and Polymers & 39 \\
\hline 29 & Advances in Membrane Technologies for Water Treatment & 22 \\
\hline 30 & Advances in Smart Medical Textiles & 19 \\
\hline 31 & Advances in Solar Heating and Cooling & 86 \\
\hline 32 & Advances in Steam Turbines for Modern Power Plants & \\
\hline 33 & Advances in Technical Nonwovens & \\
\hline 34 & Agile Data Warehousing for the Enterprise & \\
\hline
\end{tabular}




\begin{tabular}{|r|l|r|}
\hline 35 & Agile Software Architecture & 1 \\
\hline 36 & Agile Systems Engineering & 33 \\
\hline 37 & Aging and Decision Making & 58 \\
\hline 38 & Agricultural and Horticultural Engineering & 14 \\
\hline 39 & Aircraft System Safety & 31 \\
\hline 40 & Alcohol and Its Biomarkers & 22 \\
\hline 41 & Algebraic and Discrete Mathematical Methods for Modern Biology & 30 \\
\hline 42 & Alkali Metal Orthophosphates & 16 \\
\hline 43 & Alzheimer's Disease & 25 \\
\hline 44 & Amazonite & 18 \\
\hline 45 & Ambiente Bentônico & 11 \\
\hline 46 & Ambiente Pelágico & 10 \\
\hline 47 & An Emergent Theory of Digital Library Metadata & 1 \\
\hline 48 & An Introduction to Farm Organisation \& Management (Second Edition) & 34 \\
\hline 49 & An Introduction to Stochastic Orders & 6 \\
\hline 50 & Anaerobiosis and Stemness & 31 \\
\hline
\end{tabular}

Pada Tabel 1.2 dapat di lihat judul- judul e-book yang sering di unduh oleh mahaswa/i Universitas Islam Indonesia dalam database online ScienceDirect pada bulan Januari- Juni 2018.

\section{Statistik Pengunduhan E-Jurnal}

Adapun e-jurnal yang dicari dan di unduhan pada ScienceDirect di Perpustakaan Universitas islam pada bulan Januari- Juni 2018, dapat di lihat pada tabel berikut:

Tabel 1.3 Tabel e-Jurnal yang di cari bulan Januari- Juni 2018

\begin{tabular}{|l|l|}
\hline \multicolumn{1}{|c|}{ Bulan } & \multicolumn{1}{c|}{$\mathbf{2 0 1 8}$} \\
\hline Januari & 4.120 \\
\hline Februari & 2.776 \\
\hline Maret & 15.287 \\
\hline April & 13.353 \\
\hline Mai & 10.371 \\
\hline Juni & 4.135 \\
\hline Total & 50.042 \\
\hline
\end{tabular}

Dari Tabel 1.3 dapat dilihat bahwa e-jurnal pada ScienceDirect paling banyak di cari pada bulan maret.

Tabel 1.4 Tabel e-Jurnal yang di unduh bulan Januari- Juni 2018

\begin{tabular}{|l|r|}
\hline \multicolumn{1}{|c|}{ Bulan } & \multicolumn{1}{c|}{$\mathbf{2 0 1 8}$} \\
\hline Januari & 9.454 \\
\hline Februari & 35.198 \\
\hline Maret & 34.143 \\
\hline April & 34.801 \\
\hline Mai & 17.207 \\
\hline
\end{tabular}




\begin{tabular}{|l|r|}
\hline Juni & 10.901 \\
\hline Total & 141.704 \\
\hline
\end{tabular}

Dari Tabel 1.4 dapat dilihat bahwa e-jurnal pada ScienceDirect paling banyak unduh adalah bulan Februari, April dan Maret.

Tabel 1.5 Tabel e-Jurnal yang di unduh per bagian bulan Januari- Juni 2018

\begin{tabular}{|l|r|}
\hline \multicolumn{1}{|c|}{ Bulan } & \multicolumn{1}{c|}{$\mathbf{2 0 1 8}$} \\
\hline Januari & 3.024 \\
\hline Februari & 2.269 \\
\hline Maret & 7.471 \\
\hline April & 7.003 \\
\hline Mai & 5.447 \\
\hline Juni & 2.215 \\
\hline Total & 27.429 \\
\hline
\end{tabular}

Dari Tabel 1.5 dapat dilihat bahwa e-jurnal pada ScienceDirect paling banyak unduh perbagian adalah bulan Maret, April dan Mei.

Tabel 1.6 Tabel e-Jurnal yang di unduh abstrak bulan Januari- Juni 2018

\begin{tabular}{|l|r|}
\hline \multicolumn{1}{|c|}{ Bulan } & \multicolumn{1}{c|}{$\mathbf{2 0 1 8}$} \\
\hline Januari & 1.396 \\
\hline Februari & 966 \\
\hline Maret & 3.441 \\
\hline April & 3.796 \\
\hline Mai & 2.730 \\
\hline Juni & 1.190 \\
\hline Total & 13.519 \\
\hline
\end{tabular}

Dari Tabel 1.6 dapat dilihat bahwa e-jurnal pada ScienceDirect paling banyak di unduh hanya bagian abstrak adalah bulan April, Maret dan Mei.

Adapun 50 (lima puluh) Top Ranking e-jurnal yang sering di unduh adalah:

Tabel 1.7 Top List Judul e-book

\begin{tabular}{|r|l|r|}
\hline 1 & Procedia - Social and Behavioral Sciences & 6840 \\
\hline 2 & Journal of Business Research & 3709 \\
\hline 3 & European Journal of Operational Research & 3322 \\
\hline 4 & Journal of Cleaner Production & 3303 \\
\hline 5 & Procedia Computer Science & 2374 \\
\hline 6 & International Journal of Production Economics & 2122 \\
\hline 7 & Procedia Economics and Finance & 1949 \\
\hline 8 & Computers in Human Behavior & 1852 \\
\hline 9 & Journal of Banking \& Finance & 1782 \\
\hline
\end{tabular}




\begin{tabular}{|c|c|c|}
\hline 10 & Renewable and Sustainable Energy Reviews & 1634 \\
\hline 11 & Economic Modelling & 1459 \\
\hline 12 & Procedia Engineering & 1391 \\
\hline 13 & Journal of Econometrics & 1360 \\
\hline 14 & Energy Procedia & 1355 \\
\hline 15 & Energy Policy & 1285 \\
\hline 16 & Technological Forecasting and Social Change & 1085 \\
\hline 17 & Expert Systems with Applications & 1056 \\
\hline 18 & Energy & 1010 \\
\hline 19 & Applied Ergonomics & 942 \\
\hline 20 & Journal of Financial Stability & 922 \\
\hline 21 & Research in International Business and Finance & 919 \\
\hline 22 & Procedia CIRP & 875 \\
\hline 23 & Applied Energy & 862 \\
\hline 24 & Procedia Manufacturing & 840 \\
\hline 25 & Journal of Retailing and Consumer Services & 801 \\
\hline 26 & Energy Economics & 785 \\
\hline 27 & Tourism Management & 721 \\
\hline 28 & International Journal of Information Management & 713 \\
\hline 29 & International Review of Economics \& Finance & 695 \\
\hline 30 & Bioresource Technology & 660 \\
\hline 31 & Personality and Individual Differences & 660 \\
\hline 32 & Journal of International Money and Finance & 646 \\
\hline 33 & Journal of Economic Dynamics and Control & 597 \\
\hline 34 & Science of The Total Environment & 596 \\
\hline 35 & World Development & 592 \\
\hline 36 & Journal of Corporate Finance & 591 \\
\hline 37 & Renewable Energy & 577 \\
\hline 38 & International Review of Financial Analysis & 554 \\
\hline 39 & $\begin{array}{l}\text { Journal of International Financial Markets, Institutions and } \\
\text { Money }\end{array}$ & 548 \\
\hline 40 & Computers \& Industrial Engineering & 545 \\
\hline 41 & International Journal of Hospitality Management & 540 \\
\hline 42 & Economics Letters & 504 \\
\hline 43 & Journal of Financial Economics & 491 \\
\hline 44 & IFAC-PapersOnLine & 478 \\
\hline 45 & IFAC Proceedings Volumes & 467 \\
\hline 46 & Food Chemistry & 462 \\
\hline 47 & Information \& Management & 461 \\
\hline 48 & Pacific-Basin Finance Journal & 461 \\
\hline 49 & Physica A: Statistical Mechanics and its Applications & 461 \\
\hline 50 & Telematics and Informatics & 453 \\
\hline
\end{tabular}


Pada Tabel 1.7 dapat di lihat judul- judul e-jurnal yang sering di unduh oleh mahaswa/i Universitas Islam Indonesia dalam database online ScienceDirect pada bulan Januari- Juni 2018.

\section{Mengevaluasi Koleksi Dengan Tiga Metrik}

Melanggan sebuah database online yang memberikan statistik keterpakaian koleksi, sangat membantu perpustakaan dalam mengevaluasi dalam penggunaan koleksi digital. Hahn dan Faulkner (seperti dikutip Hult, 2007), dari University of Maryland Libraries, telah mengembangkan metode menggunakan statistik penggunaan, jika koleksi elektronik di anggap relevan sesuai dengan kebutuhan pengguna. Pertama mereka mengevaluasi koleksi yang ada, mengembangkan tiga metrik: biaya rata-rata per artikel, biaya rata-rata per penggunaan, dan penggunaan konten yang sesuai. Mereka merasa jumlah artikel yang diterbitkan dalam setahun, dan penggunaan artikel-artikel itu, sangat membantu dalam evaluasi pengadaan bahan pustaka khususnya koleksi elektronik. Untuk menghitung biaya rata-rata e-jurnal dan e-book (harga dibagi dengan jumlah e-jurnal dan e-book), biaya ratarata per akses (harga dibagi dengan jumlah unduhan), dan penggunaan konten-disesuaikan (jumlah akses dibagi dengan jumlah artikel.)

\section{Menghitung biaya rata-rata e-jurnal dan e-book}

Untuk menghitung biaya rata-rata e-jurnal dan e-book adalah harga dibagi dengan jumlah e-jurnal dan e-book. Jumlah koleksi yang ada dalam ScienceDirect adalah 4.038 ejurnal dan 28.289 e-book sehingga totalnya 32.327 .

Harga Artikel = Harga melanggan : Jumlah artikel

$=3.500 .000 .000: 32.327$

$=108.268,63 /$ e-jurnal atau e-book

\section{Menghitung biaya rata-rata per akses}

Untuk menghitung biaya rata-rata per akses e-jurnal dan e-book adalah harga dibagi dengan jumlah unduhan full-text e-jurnal dan e-book. Jumlah unduhan yang ada dalam ScienceDirect pada Perpustakaan Universitas Islam Indonesia adalah 141.704 e-jurnal dan 20.146 e-book sehingga totalnya 161.850 unduhan.

Harga Perakses $=$ Harga melanggan : Jumlah unduhan

$$
\begin{aligned}
& =3.500 .000 .000: 161.850 \\
& =120,138674 / \text { akses e-jurnal atau e-book }
\end{aligned}
$$

3. Menghitung penggunaan konten yang sesuai

Untuk menghitung penggunaan konten yang sesuai adalah jumlah akses dibagi dengan jumlah e-jurnal dan e-book. Jumlah akses yang ada dalam ScienceDirect pada Perpustakaan Universitas Islam Indonesia, termasuk akses per bagian 27.429, aksel pencarian 50.042, akses abstrak 13.519 dan akses full- text 141.704 sehingga total akses pada bulan Januari- Juni 2018 adalah 90.990 akses.

Penggunaan Konten = Jumlah akses : Jumlah e-jurnal e-book

$$
\begin{aligned}
& =90.990: 32.327 \\
& =2.814
\end{aligned}
$$

Setelah melakukan evaluasi mengenai biaya rata-rata e-jurnal dan e-book adalah Rp. 108.268,63, biaya rata-rata per akses adalah Rp. 120,138674/ akses, dan penggunaan konten yang sesuai, masing- masing mahasiswa/i Universitas Islam Indonesia mengakses 
setidaknya 3 (tiga) e-jurnal atau e-book yang sesuai dan relevan dengan informasi yang di butuhkan.

\section{E. KESIMPULAN}

Database online sangat membantu pustakawan dalam memberikan pelayanan kepada pengguna. Salah satu database online yang di langgan oleh Perpustakaan Universitas Islam Indonesia adalah ScienceDirect. Setelah mengevaluasi biaya, baik itu harga e-jurnal dan ebook dan juga harga akses e-jurnal dan e-book, dalam berlangganan ScienceDirect sangat menguntungkan Perpustakaan Universitas Islam Indonesia. Hal tersebut dapat dilihat dari keterpakaian sumber informasi dalam format digital yang di sediakan oleh ScienceDirect, menyebabkan harga artikel serta biaya akses jauh lebih murah dari pada tidak melanggan ScienceDirect. Maka dalam mengambil kebijakan pengadaan bahan pustaka koleksi elektronik, penulis menyarankan untuk tetap melanggan ScienceDirect.

\section{DAFTAR PUSTAKA}

Arikunto, Suharsimi. 2010. Prosedur Penelitian : Suatu Pendekatan Praktik. Jakarta : Rineka Cipta

Darmono. 2001. Manajemen dan Tata Kerja Perpustakaan Sekolah. Jakarta : Grasindo Indonesia. 1960. Undang- Undang Republik Indonesia No. 7. Jakarta

Jaya, Indra dan Ardat. 2013. Penerapan Statistik Untuk Pendidikan. Medan: Cita Pustaka Khusnia, Dina dan Berliana Kusuma Riasti. 2014. Pembuatan Website Profil Sekolah Menengah Pertama Negeri 1 Kalitidu Bojonegoro. Indonesian Journal on Networking and Security Vol. 3 No. 1

Musyawarah, Rina. 2005. Membangun Aplikasi Data Base Berbasis Web untuk Pemula. Jakarta : Elex Media Komputindo Kelompok Gramedia.

Nugroho, Nur Cahyo dan Bambang Eka Purnama. 2012. Perancangan Inovasi Konten Web Radio Streaming Dan Podcasting Pada Radio Puspa Fm Pacitan . Journal Speed Sentra Penelitian Engineering dan Edukasi Vol. 4 No. 4

Prabowo, Aan dan Heriyanto. 2013. Analiss Pemanfaatan Buku Elektronik (E-Book) Oleh Pemustaka di Perpustakaan SMA Negeri 1 Semarang. Jurnal Ilmu Perpustakaan Volume 2. No.2.

Rusydi, Ibnu. 2014. Pemanfaatan E-jurnal Sebagai Media Informasi Digital. Jurnal Iqra' Vol. 08 No.02

Sugiyono. 2011. Statistika untuk Penelitian. Bandung: Alfabeta.

Sulistyo-Basuki. 2001. Pengantar Ilmu Perpustakaan. Jakarta: Gramedia Pustaka Utama.

Supriadi, Eko. 2013. Simulasi Digital. Malang: Kemdikbud

Suwarno , Wiji .2011. Perpustakaan dan Buku : Wacana Penulisan dan penerbitan. Jogjakarta : Ar-Ruzz Media. 